
RESPOSTA EM TUMORES SÓLIDOS?

RECIST v1.1 (Response Evaluation Criteria In Solid Tumours)

Medir a redução tumoral e determinar a progressão da doença de acordo com um método único constituiu uma ferramenta clínica de grande importância na avaliação da resposta objetiva a tratamentos oncológicos. O critério RECIST é mundialmente aceito e tem sido utilizado na determinação dos objetivos dos estudos clínicos, seja por investigadores, grupos acadêmicos, indústria farmacêutica ou entidades governamentais.

A fim de resolver uma série de questões práticas desde a sua publicação em 2000, e após a coleta e simulação de dados de 


\begin{tabular}{|c|c|c|c|}
\hline Item & RECIST 1.0 & RECIST 1.1 & Racional \\
\hline $\begin{array}{l}\text { Tamanho das } \\
\text { lesões tumorais } \\
\text { mensuráveis }\end{array}$ & $\begin{array}{c}\text { TC: } \\
10 \text { mm espiral } \\
20 \mathrm{~mm} \text { não-espiral } \\
\text { Clinicamente: } \\
20 \mathrm{~mm} \\
\text { Linfonodos: nao mencionado }\end{array}$ & $\begin{array}{c}\text { TC: (não é necessário TC espiral) } \\
10 \text { mm } \\
\text { Clinicamente: } \\
10 \text { mm (deve ser mensurável) } \\
\text { Linfonodos na TC: } \\
15 \text { mm no diâmetro para lesão alvo } \\
10-<15 \text { mm para lesão não-alvo } \\
<10 \text { mm não é considerado patológico }\end{array}$ & $\begin{array}{l}\text { Espessura dos cortes no aTC é geralmente } \\
5 \mathrm{~mm} \text { ou menor. } \\
\text { É melhor limitar o intervalo entre os cortes } \\
\text { para } 5 \mathrm{~mm} \\
\text { Linfonodos são estruturas normais e existia a } \\
\text { necessidade de definir qual é seu tamanho } \\
\text { patológico. }\end{array}$ \\
\hline
\end{tabular}

Outras lesões tumorais mensuráveis

Determinação da extensão do tumor Número de lesões-alvo

Critério de Resposta para as lesões-alvo

Critério de resposta em lesões não-alvo

\section{Novas lesões} tumorais

\section{Como confirmar a resposta}

FDG-PET na determinação de novas lesões tumorais
Para RC e RP: 0 critério deve ser confirmado quatro semanas após a documentação inicial
Inclui lesões ósseas e císticas

5 lesões (Duas por órgão)

RC:

Linfonodos não eram utilizados

PD:

$20 \%$ de aumento na soma das lesões ou nova(s) lesão(ões).

Progressão inequívoca das lesões não-alvo era considerada PD

Detalhes sobre PD a fim de explicar melhor que a mudança deve ser representativa de toda a doença e não o aumento de uma única lesão.

RECIST é utilizado em estudos aonde a progressão livre de doença é um dos objetivos e nem todos os pacientes têm lesão-alvo mensurável no início do estudo.

Manter este requerimento SOMENTE para estudos não-randomizados em que o objetivo primário é a resposta tumoral

Se FDG-PET é negativo inicialmente: Define-se "Progressão" se houver uma nova lesão no acompanhamento

\section{Se FDG-PET não foi utilizado no início}

Define-se "Progressão" se houver uma lesão PET positiva em uma nova lesão determinada pelo CT

Não é progressão se nenhuma nova lesão for definida pelo TC

\section{Informação adicional}

A revisão do banco de dados mostrou que não há perda de informação se o número de lesões for reduzida de 10 para 5.0 máximo de duas lesões por órgão é suficiente

Determina o tamanho normal dos linfonodos PD: além do aumento em 20\% na soma das lesões, é necessário também aumento absoluto em $5 \mathrm{~mm}$ a fim de evitar classificar-se como $\mathrm{PD}$, quando a soma total e muito pequena e 20\% de aumento está dentro do erro de medida.

Evitar as dúvidas que ocorrem na versão do RECIST 1.0, em que alguns consideravam que PD podia ser definida se qualquer uma das lesões não-alvo aumentassem, mesmo quando a lesão-alvo era estável ou estava respondendo.

Definir melhor quando uma lesão deve ser considerada uma nova lesão e, portanto, PD

0 banco de dados mostrou que as taxas de resposta aumentam quando a confirmação não é utilizada. A única circunstância é em estudos clínicos não-comparativos, em que o objetivo é a resposta tumoral.

Utilização de FDG-PET

Legenda: TC:Tomografia Computadorizada; RC: Resposta completa; RP: Resposta parcial; PD: Progressão da doença; DE: Doença estável. Tempo de sobrevida livre da doença é o intervalo entre o desaparecimento completa/parcial e seu reaparecimento; Tempo total de sobrevida é o intervalo entre a resposta completa/ parcial até o momento da morte. 
mais de 6.500 pacientes e de uma vasta revisão da literatura, a versão 1.1 do RECIST foi publicada recentemente.

\section{0 que é que NÃO mudou no RECIST 1.1}

- A doença tumoral continua a ser determinada pela a avaliação do tamanho tumoral.

- As lesões tumorais devem ser mensuráveis uni ou bidimensionalmente

- O critério de resposta:

- Resposta completa (RC)

- Resposta parcial (RP): 30\% na redução da soma das lesões tumorais em relação às medidas iniciais

- Doença estável (DE)

- Progressão da doença (PD): 20\% no aumento da soma das lesões tumorais em relação às medidas iniciais

\section{0 que é que mudou no RECIST 1.1}

- O número de lesões-alvo necessárias para determinar a resposta tumoral foi reduzido de 10 para o máximo de 5, e de 5 para 2 por órgão anatômico.

- Linfonodos/nódulos patológicos são também considerados lesões tumorais mensuráveis se o seu diâmetro menor for superior a $15 \mathrm{~mm}$.

- Linfonodos/nódulos com diâmetro menor $<10$ mm são considerados normais.

- O diâmetro menor das lesões tumorais deve ser utilizado no cálculo da soma das lesões e na determinação da resposta tumoral.
- Confirmação da resposta não é mais necessária em estudos clínicos randomizados, visto que o controle serve como um meio apropriado de interpretação dos dados.

- Progressão da doença é agora definida como o aumento de $20 \%$ aumento da soma das lesões tumorais em relação às medidas iniciais, mais o aumento absoluto de $5 \mathrm{~mm}$ a fim de evitar que se declare PD quando a soma das lesões é muito pequena.

- Além disso, um guia sobre o que é "progressão inequívoca" das lesões não mensuráveis/lesões não-alvo e, finalmente, como interpretar FDG-PET scan e um apêndice com recomendações sobre de como melhor avaliar as imagens.

Vale lembrar que a avaliação bidimensional dos tumores ainda é válida e que a única exceção é o uso do FDG-PET como um método adicional de determinação de PD (Tabela 1).

Clinical Research Physician

Marcelo Marotti

AstraZeneca Clinical Development

Alderley Park - England

Referências

1. Eisenhauer EA, Therasse P; Bogaerts J, Schwartz LH, Sargent D, Ford R, et al. New response evaluation criteria in solid tumours: revised RECIST guideline (version 1.1). Eur J Cancer. 2009;45(2):228-47.

2. Therasse P, Arbuck SG, Eisenhauer EA, Wanders J, Kaplan RS, Rubinstein $L$, et al. New guidelines. to evaluate the response to treatment in solid tumors (RECIST Guidelines). J Natl Cancer Inst. 2000;92(3):205-16. 